\title{
The Effects of TBLT's Strong Form and Weak Form on ESL Students' Vocabulary Acquisition
}

\author{
Rui Wu \\ English Department, Beijing Information Technology College, Beijing, China
}

\begin{abstract}
The present study applied task-based language teaching (TBLT) approach to English vocabulary teaching of vocational college students. Based on the different ideas of TBLT types-the strong form (i.e. the strong task-based approach) and the weak form (i.e. the weak task-based approach), it designed different teaching procedures aiming to explore different effects of the two types on English vocabulary acquisition. The result showed that the students as a whole had a better learning result when they were taught by the strong form of TBLT, especially when dealing with productive vocabulary. However, the strong form didn't seem to have as good an effect on lower level students as on upper and middle level ones.
\end{abstract}

Index Terms - TBLT, strong form, weak form, vocabulary teaching

\section{INTRODUCTION}

As an important constituent of language knowledge, vocabulary is the basis of language acquisition. However, in vocational colleges of China, most students' vocabulary competence is at a lower stage and hinders their development of English learning. Task-based language teaching approach has been in existence for over 20 years. Centering around communicative tasks, it aims to improve students' application ability of the English language during the process of using the language to finish tasks. Nevertheless, there has been a long dispute over the two types of TBLT--the strong form and the weak form. Although some scholars consider the weak form more suitable for English learners in China (Gong \& Luo, 2006), few empirical studies were conducted to prove it, let alone their effects on vocabulary acquisition.

Therefore, the present study applied TBLT to college English teaching and designed separate teaching procedures based on different ideas of the strong form and the weak form, in order to explore their various teaching effects on vocabulary acquisition, thus offering suggestions for college English vocabulary teaching.

\section{LITERATURE REVIEW}

\section{A. Different Ideas of the Strong and Weak Forms of TBLT}

Task-based language teaching, also known as task-based instruction (TBI), derived from communicative language teaching (CLT), focusing on the use of authentic language and asking students to do meaningful tasks using the target language. As a student-oriented and task-centered teaching approach, it advocates that students acquire language in the process of accomplishing tasks. However, there has been a long dispute over the strong form and the weak form, which are the two types of TBLT, since it was introduced twenty years ago. Scholars have different views on what is a task. The advocates for strong form believe that a task is an intentional and a communicative activity that learners fulfill through the use of target language (Willis, 1996). Therefore, only a communicative task can be called a task, while other activities can be merely called practice. In contrast, supporters for the weak form claim that tasks can be divided into communicative tasks and enabling tasks. The latter refers to various language practices that support the communicative tasks (Estair \& Zanon, 1994).

In the way of teaching, the major distinction between the strong and the weak forms lies in when and how to teach language knowledge. Advocates for the strong form insist that a primary characteristic of TBLT should be that learners are free to use any language form in order to achieve a communicative goal and teachers are not supposed to provide language forms in advance (Willis, 1996), for those language features that students want to use but do not know how to use are the optimal teaching goals of TBLT (Ellis, 2003). Language knowledge appears naturally during the process of using the language to fulfill tasks. It is obtained through meaning negotiation, focusing on forms, interaction and scaffolding, and consolidated through post-task practices. In contrast, supporters for the weak form insist that language knowledge should appear before the task and be consolidated during the task. That is, teaching should start from noncommunicative practice of language forms to controllable communicative tasks, and finish up in real communicative tasks (Littlewood, 2004). In that way, teachers are ensuring that students communicate within their limited language ability while guiding students to advance toward authentic communication (Gong \& Luo, 2006).

B. Current Research Findings of Vocabulary Teaching

1. Research from the perspective of direct and indirect vocabulary teaching 
Generally, the vocabulary teaching methods are divided into direct method and indirect method. From the angle of the learner, they are explicit learning and implicit learning. When direct method is taken, learners focus their attention on the subjective and conscious activities and exercises that are directly related to vocabulary. When indirect method is taken, vocabulary is not the direct object of study, but part of the whole study. Learners focus their attention on other aspects of learning, especially on the messages conveyed by the language. They have mastered vocabulary only incidentally in order to complete the task (Sun, 2011). Dong (2001) conducted an experimental study on the vocabulary teaching of college English majors. Sun (2011) made a comparative study on the direct vocabulary teaching method and the indirect method in grade three English teaching of a senior high school. Both of their research found that when teachers combined direct method with indirect method, students' vocabulary acquisition was far more efficient than using any method alone, especially for productive vocabulary.

2. Research from the perspective of vocabulary learning strategies

A large number of scholars have explored vocabulary teaching from the perspective of vocabulary learning strategies, and have achieved fruitful results. Vocabulary learning strategies are divided into two layers: meta cognitive strategies and cognitive strategies. The former includes planning, self-assessment, self-examination and selective attention allocation strategies, etc. And the latter includes concrete methods such as rote memorization, classification, association, lexical chunks, spelling, context, dictionary search, guessing, counseling, doing exercises, word lists, keywords and semantic processing, etc. (Wu \& Wang, 1998; Zhang, 2006) Most cognitive strategies are used in direct vocabulary teaching, while indirect vocabulary teaching mainly uses context, dictionary search and counseling strategies. In this paper, we do not distinguish between learning strategy and teaching strategy, because they are the same thing from different angles. When the teacher is guiding the students to use a certain strategy in class, the teacher is using a teaching strategy, while the students are using a learning strategy.

Some researchers made investigations on students' selection of learning strategies and the correlation between their learning strategies and their learning result. Among the many vocabulary learning strategies, context strategy was studied most. It derived from communicative language teaching, and considers context crucial to the way that meanings can appropriately be expressed and understood. Wu and Wang (1998) carried out their investigation among non-English major college students and the result showed there was a great correlation between learning strategies and the quality and quantity of vocabulary knowledge; learning in context was the most effective learning strategy, while rote memorization was the least efficient one. Other scholars made empirical research on the connection between vocabulary learning strategies and their learning effect. Zhang (2006)'s study strongly suggested that the meta cognitive strategies were crucial to the success of vocabulary learning and the context-oriented sources were more effective than other strategies. R. Zhao (2010) also explored and attempted the context strategy. She developed her teaching in three levels: lexical context, grammatical context and situational context. Her study showed that the use of the three levels of context in vocabulary teaching conformed to the laws of memory and cognition, and was conducive to improving the learning interest and effect. Under the guidance of communicative approach, Guan (2016) applied context strategy to vocabulary teaching in her experimental class. Her comparative study showed that context strategy played a significant role in improving the effectiveness of vocabulary teaching in senior high school.

3. Research from the perspective of language teaching approaches

Vocabulary teaching is an important part of language teaching. Various language teaching approaches have revealed vocabulary teaching strategies to some extent. For example, the communicative language teaching (CLT) approach admires indirect learning and disapproves of the study of purely linguistic forms. According to Krashen (Krashen \& Terrell, 1983), language learning comes about through using target language communicatively (learners' needs considered), rather than through practicing language skills. Scholars favoring CLT believe that the words to teach should be decided according to learners' need and fully successful vocabulary acquisition is a by-product of communication. Gui (2011) applied CLT to English vocabulary teaching in a senior high school. First, she endeavored to make students familiar with the relevant vocabulary by explaining and giving examples. Then, she guided students to use the words by setting up communicative situations and organizing communicative activities. Her research found that CLT could bring learners' imagination into full play and make vocabulary learning more practical, thus effectively improving students' vocabulary competence.

Task-based approach is the development of communicative approach. A few scholars have studied vocabulary teaching under TBLT. Wang (2012) investigated English vocabulary teaching in senior high schools. After questionnaires and interviews and based on TBLT theory, she designed three-step vocabulary teaching method: concentrated direct teaching, hierarchical indirect teaching and extended teaching. The teaching method she designed actually belonged to the weak form of TBLT approach, where required vocabulary was presented and relevant exercises were carried out before the students started their task.

In summary, most of the literature investigated the use of vocabulary learning strategies of students, and a few of the literature studied the relationship between vocabulary learning strategies, direct/indirect vocabulary teaching methods and vocabulary acquisition effect, but there are few empirical researches on the effect that language teaching approaches have on vocabulary acquisition. Under the strong task-based approach, vocabulary is learned indirectly and incidentally, so it is a by-product of communicative tasks, which results in the different vocabulary that each student acquires. Therefore, it is definitely hard to have an accurate measurement of vocabulary learning effect. These 
difficulties may lead to the rare studies on the correlation between task-based language teaching and vocabulary acquisition effect.

\section{RESEARCH DESIGN}

\section{A. Research Questions}

The present study implemented vocabulary teaching experiment using the strong and weak forms of TBLT, trying to explore their effects on vocabulary acquisition so as to put forward suggestions for vocabulary teaching. The following questions were addressed in the present study: whether there is a significant difference between the strong form and the weak form of TBLT in the effect of vocabulary teaching; what effects the two forms have on vocabulary learning of girls and boys respectively; what effects the two forms have on vocabulary learning of upper, middle and lower level students respectively.

\section{B. Subjects}

The subjects were students from two classes in the second grade of a vocational college. There were 36 persons in group A, including 25 males and 11 females, and 37 persons in group B, including 27 males and 10 females.

\section{Research Method}

Quantitative research method was employed in this empirical study.

\section{Experiment Procedures}

The experimental teaching of Group A and Group B lasted 8 weeks by the same teacher. Group A were taught under the strong form during the first four weeks while Group B by the weak form; during the second four weeks, Group A were taught under the weak form while Group B by the strong form. A written task was given at the beginning of every class, such as writing a composition, completing an introduction of a particular scenic spot, etc. The tasks of Group A and Group B were the same each time. The number of vocabulary items required to learn for either group was also the same, that was, 15 words each time, including five words that needed to be mastered productively. Under the strong form, relevant words were not provided before the task. When students met with difficulties with words during their completing the task, they solved the problems by themselves using strategies such as looking up dictionaries and counseling. After the task was finished, they selected 15 words that they were not familiar with on their own. The 15 words, including the 5 words needed to be mastered productively, were checked by the teacher before they were approved of as required words and taken down on students' notebooks. Then, students needed to make sentences with the 5 productive words with the help of the dictionary and the teacher, and write them down on their notebook. While under the weak form, the teacher provided words that students might use before they started carrying out the task, together with the words' explanation, sample sentences and relevant practices. The 15 required words, including the 5 words needed to be mastered productively, were designated by the teacher after the completion of the task.

Both Group A and Group B were tested twice during the eight-week experimental period with the first test taken at the end of the fourth week and the second at the end of the eighth week, in order to evaluate the vocabulary learning effects of students when they were taught by the strong form and weak form of TBLT respectively. When examining the effect of the weak form, a dictation of the 60 words, which were designated by the teacher in the previous four periods of lessons, was implemented with the teacher speaking out the Chinese translation and the students writing out their English equivalents in order to test the learning result of receptive vocabulary. Then, the teacher selected 10 words from them, which were previously required to be used productively, and asked students to make sentences with them so as to test the learning result of productive vocabulary. When examining the effect of the strong form, the teacher made separate test papers for each student according to the words they took down on their notebooks which were collected by the teacher beforehand. Each test paper consisted of 60 words that were required to be translated from Chinese into English. The teacher selected 10 words for each paper and asked students to make sentences with them. Each student had a different paper when the effect of strong form was examined because the words to be examined were mainly decided by the students themselves in the previous four lessons.

The papers were collected and graded by the teacher. Each word carried one point and 60 words carried 60 points altogether. If one individual letter was misspelled but did not affect the meaning of expression, 0.5 point was subtracted; if the word's meaning was affected or if two or more letters were misspelled, then zero point was given. Each sentence carried 4 points and the total score for each paper was 100. The scores of the papers were recorded and the data were input into SPSS 17 to be analyzed.

\section{RESULTS AND DiSCUSSION}

First, the effects that the strong form and the weak form had on students as a whole were analyzed; then the effects that the two forms had on male students and female students separately were tested; lastly, the effects that the two forms had on upper level, middle level and lower level students were examined respectively. The researcher endeavored to find out whether there was a significant difference between the two types of TBLT. 


\section{A. The Effects of the Strong and Weak Forms on the Whole Students}

The differences of students' scores under the strong and the weak task-based approaches were detected using paired sample $\mathrm{T}$ test. The result is as follows.

TABLE I

THE DIFFERENCES BETWEEN STRONG AND WEAK FORMS FOR WHOLE STUDENTS

\begin{tabular}{|c|c|c|c|c|c|}
\hline & Method & Mean & $\mathrm{N}$ & $\begin{array}{l}\text { Paired Samples } \\
\text { Correlations }\end{array}$ & $\begin{array}{l}\text { Sig. (2-tailed) of } \\
\text { Paired Differences }\end{array}$ \\
\hline \multirow{2}{*}{$\begin{array}{l}\text { Total Scores of } \\
\text { Papers }\end{array}$} & Strong Form & 75.97 & 73 & \multirow[t]{2}{*}{.965} & \multirow[t]{2}{*}{.000} \\
\hline & Weak Form & 73.95 & 73 & & \\
\hline \multirow{2}{*}{$\begin{array}{l}\text { Scores of Receptive } \\
\text { Words }\end{array}$} & Strong Form & 44.06 & 73 & \multirow[t]{2}{*}{.956} & \multirow[t]{2}{*}{.552} \\
\hline & Weak Form & 43.95 & 73 & & \\
\hline \multirow{2}{*}{$\begin{array}{l}\text { Scores of Productive } \\
\text { Words }\end{array}$} & Strong Form & 31.92 & 73 & \multirow[t]{2}{*}{.670} & \multirow[t]{2}{*}{.000} \\
\hline & Weak Form & 30.01 & 73 & & \\
\hline
\end{tabular}

As can be seen from the table, when students receive vocabulary teaching in the strong and weak forms respectively, their scores show a significant difference (Sig.< 0.05). However, that difference mainly comes from the scores of productive words. As for the receptive words, there is no significant difference between the strong and the weak forms (Sig. > 0.05). It may due to the fact that students merely need to comprehend the receptive words and be able to spell them right, which is a lot easier than what students need to do with the productive words, which are required to be used in context correctly. Besides, when the weak form is taken, the exercises of language forms that the teacher leads students to do before the task help to consolidate students' memorization of the receptive words.

For the learning effect of productive vocabulary, the strong form is obviously superior to the weak form (Sig.<0.05). It may be explained by the following facts. First, the indirect vocabulary teaching method is employed in the strong task-based approach. In the lessons of strong form TBLT, the required words appear naturally during the process of students' completing their tasks, and those words are just the ones that students actually need to use in their tasks. As a result, they leave a deep impression on the students. Second, based on the previous research on the direct and indirect vocabulary teaching, the teacher added a step to the original strong task-based language teaching in the present experiment: after the students finished the tasks, they were asked to use the words to make sentences on their own employing the strategies such as looking up dictionaries and consulting teachers. In this way, they combined the indirect vocabulary learning method with the direct method, which improved their learning effect. This result was consistent with the findings of Dong (2001) and Sun (2011) which suggested that the combination of direct and indirect methods could greatly improve vocabulary acquisition effect. However, under the weak task-based approach, new words and their sample sentences are presented before the task. The learning process is controlled by the teacher and the students complete the relevant exercises assigned by the teacher mechanically and passively, thus affecting their learning result.

\section{B. The Effects of the Strong and Weak Forms on Male and Female Students Respectively}

Then, the effects of the strong and weak forms on male students and female students separately were examined through paired sample T test.

TABLE II

THE DIFFERENCES BETWEEN STRONG AND WEAK FORMS FOR MALE AND FEMALE STUDENTS RESPECTIVELY

\begin{tabular}{|c|c|c|c|c|c|}
\hline 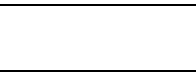 & Method & Mean & $\mathrm{N}$ & $\begin{array}{l}\text { Paired Samples } \\
\text { Correlations }\end{array}$ & $\begin{array}{l}\text { Sig. (2-tailed) of } \\
\text { Paired Differences }\end{array}$ \\
\hline \multirow[t]{2}{*}{ Male Students } & Strong Form & 75.20 & 52 & \multirow[t]{2}{*}{.962} & \multirow[t]{2}{*}{.000} \\
\hline & Weak Form & 73.04 & 52 & & \\
\hline \multirow[t]{2}{*}{ Female Students } & Strong Form & 77.90 & 21 & \multirow{2}{*}{.982} & \multirow{2}{*}{.003} \\
\hline & Weak Form & 76.24 & 21 & & \\
\hline
\end{tabular}

As is shown in table II, there is a significant difference between the effects of the strong form and the weak form of TBLT (Sig.<0.05), whether on male students or on female students, and the average scores of the strong form are higher than those of the weak form. However, the difference in average scores between the two forms is 2.16 points for boys, but only 1.66 points for girls and it seems that boys benefit more than girls from the strong form. Psychological research shows that females are more field dependent than males, and males are more field independent than females. Fielddependent people tend to rely more on the environment and the people around to get clues to solve the problem, while field-independent people prefer to rely on their own to solve the problem (Hou, 1998). The strong form proposes that no sufficient language support be given before students start their task. If students meet with language difficulties during completing tasks, they should try to overcome the difficulties on their own by looking up dictionaries, surfing the Internet, consulting teachers and their classmates. Therefore, the strong task-based approach is more suitable for fieldindependent learners, that is, its effect on boys' learning result tends to be greater than that on girls.

\section{The Effects of the Strong and Weak Forms on Upper, Middle and Lower Level Students Respectively}


In the end, the effects of the strong and weak forms on upper, middle and lower level students respectively were detected through paired sample $\mathrm{T}$ test. The high score, middle score and low score segments of the vocabulary tests are divided as follows: high score $\geq 80 ; 70 \leq$ middle score $<80$; low score $<70$.

TABLE III

THE DIFFERENCES BETWEEN STRONG AND WEAK FORMS FOR UPPER, MIDDLE AND LOWER STUDENTS RESPECTIVELY

\begin{tabular}{|c|c|c|c|c|c|}
\hline & Method & Mean & $\mathrm{N}$ & $\begin{array}{l}\text { Paired Samples } \\
\text { Correlations }\end{array}$ & $\begin{array}{l}\text { Sig. (2-tailed) of } \\
\text { Paired Differences }\end{array}$ \\
\hline \multirow[t]{2}{*}{ Upper Level Students } & Strong Form & 86.94 & 27 & \multirow[t]{2}{*}{.750} & \multirow[t]{2}{*}{.000} \\
\hline & Weak Form & 82.59 & 27 & & \\
\hline \multirow[t]{2}{*}{ Middle Level Students } & Strong Form & 76.25 & 18 & \multirow[t]{2}{*}{.685} & \multirow[t]{2}{*}{.000} \\
\hline & Weak Form & 74.08 & 18 & & \\
\hline \multirow[t]{2}{*}{ Lower Level Students } & Strong Form & 65.23 & 28 & \multirow[t]{2}{*}{.668} & \multirow[t]{2}{*}{.531} \\
\hline & Weak Form & 65.55 & 28 & & \\
\hline
\end{tabular}

Table 3 shows that for students with high and middle scores, the effects of strong and weak forms on their vocabulary test scores are significantly different (Sig.<0.05), while no significant difference exists for low score students (Sig.>0.05). Previous research found that compared with poor students, excellent students employ various learning strategies more frequently, and the difference is significant in the use of context strategy and word guessing strategy (Wu \& Wang, 1998; Zhao J., 2005). Under the strong form of TBLT, Students do not have ready-made vocabulary to use, so they must play their initiative and use context, dictionary and counseling learning strategies more frequently. Therefore, it is nearly without doubt that excellent students will benefit more from the strong task-based approach.

\section{CONCLUSION}

\section{A. Suggestions on Vocabulary Teaching}

In the light of the previous analysis, some tentative suggestions on vocabulary teaching based on the strong and weak forms of TBLT are put forward as follows.

Firstly, the strong form of TBLT is recommended when the teaching goal is to improve students' language productive ability. In the strong form, students are encouraged to take initiative to learn new vocabulary actively, for learning is more effective when learners are actively involved in the learning process. When they use context, dictionary and counseling strategies, they are improving their practical language skill as well as learning how to learn. The ultimate aim of teaching is to "teach students to fish" rather than "give them fish". Only when students learn to know words, use words and keep enlarging their vocabulary can the final goal of vocabulary teaching be achieved. However, under the weak form, students' initiative in exploring new words is restrained, which is not conducive to the development of their creative thinking and the cultivation of their autonomous learning ability. But teachers had better add direct vocabulary teaching after students complete their tasks. For example, they can ask students to make sentences using the words they have learned during their tasks.

Secondly, because the strong task-based approach is not so helpful to poor students, students with weak English foundation can continue to be taught by the weak form, but teachers should gradually increase using the strong taskbased teaching for poor students, in order to help them improve their autonomous learning ability.

However, the acquisition speed of vocabulary is slow in the strong task-based approach. So, teachers should expand vocabulary after students' completion of the task, which means adding some more vocabulary related to the task but not used by the students and giving explanation, in order to make up for the lack of vocabulary and example sentences under the strong form of TBLT.

Besides, under the strong task-based approach, lessons tend to be less predictable and teachers should be always prepared for any linguistic emergency, which poses a challenge to the teachers. Therefore, teachers should keep improving themselves and try to possess a high level of language competence.

\section{B. Limitation and Future Direction of the Research}

However, the number of vocabulary involved in this research was small, and the mastery of productive words was merely tested by making sentences, which was a relatively simple evaluation form, so the result of this study needs to be verified by larger-scale tests in multiple ways.

\section{REFERENCES}

[1] Dong, Yanping. (2001). Direct and indirect L2 vocabulary learning in the communicative approach. Foreign Language Teaching and Research, 33.3, 186-192.

[2] Ellis, R. (2003). Task-based Language Learning and Teaching. Oxford: Oxford University Press.

[3] Estair, S. \& J. Zanon. (1994). Planning Class work: A Task-based Approach. Oxford: Heinemann Publishers.

[4] Gong, Yafu \& Shaoxi Luo. (2006). Task-Based Language Teaching. Beijing, China: People's Education Press.

[5] Guan, Yulan. (2016). A study on effective strategies for improving English vocabulary teaching in senior high schools. Unpublished master thesis, Shanghai Normal University, Shanghai, China. 
[6] Gui, Yuan. (2011). Application of communicative approach in English vocabulary teaching in high school. Unpublished master thesis, Chongqing Normal University, Chongqing, China.

[7] Hou, Songshan. (1998). Effects of tasks and gender on foreign language communication strategies. Journal of PLA Institute of Foreign Languages, 21.6, 20-23.

[8] Krashen, S. D. \& T. D. Terrell. (1983). The Natural Approach: Language Acquisition in the Classroom. Oxford: Pergamon Press.

[9] Littlewood, W. (2004). The task-based approach: some questions and suggestions. ELT Journal, 58.4, 319-326.

[10] Sun, Lingyu. (2011). Comparative analysis of direct English vocabulary teaching and indirect English vocabulary teaching in grade three senior high school. Unpublished master thesis, East China Normal University, Shanghai, China.

[11] Wang, Luping. (2012). A study on vocabulary teaching for senior high school students within the model of task-based language teaching. Unpublished master thesis, Chongqing Normal University, Chongqing, China.

[12] Willis, J. (1996). A Framework for Task-based Learning. Essex: Addison Wesley Longman Limited.

[13] Wu, Xia \& Qiang Wang. (1998). The vocabulary learning strategies of non-English major college students. Foreign Language Teaching and Research, 1998.1, 55-59.

[14] Zhang, Tao. (2006). An investigation into vocabulary learning strategies used by non-English majors. Teaching English in China, 29.2, 27-33.

[15] Zhao, Jizheng. (2005). An investigation into vocabulary learning strategies of non-English majors in vocational colleges. Foreign Language Teaching Abroad, 2005.3, 44-48+60.

[16] Zhao, Rongmei. (2010). Contextualization and English vocabulary teaching in senior high school. Unpublished master thesis, East China Normal University, Shanghai, China.

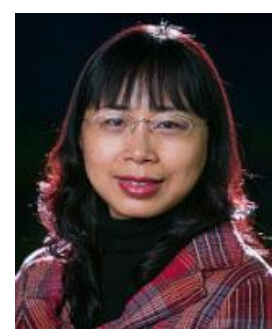

Rui Wu was born in Beijing, China in 1971. She received her M.A. Degree in applied linguistics from Beijing Institute of Technology, China in 2006. She is currently a lecturer in Beijing Information Technology College, China. Her academic research focuses on EFL teaching. 